\title{
Improved Seismic Monitoring with OBS Deployment in the Arctic: A Pilot Study from Offshore Western Svalbard
}

\author{
Authors \\ Zeinab Jeddi, Dept. of Earth Science, University of Bergen, Bergen, Norway (zeinab.jeddi@gmail.com) \\ Lars Ottemöller, Dept. of Earth Science, University of Bergen, Bergen, Norway (lars.ottemoller@uib.no) \\ Mathilde B. Sørensen, Dept. of Earth Science, University of Bergen, Bergen, Norway \\ (mathilde.sorensen@uib.no) \\ Sara Rezaei, Dept. of Earth Science, University of Bergen, Bergen, Norway (sara080785@ yahoo.com) \\ Steven J. Gibbons, Norwegian Geotechnical Institute, Oslo, Norway (steven.gibbons@ ngi.no) \\ Marte L. Strømme, Dept. of Earth Science, University of Bergen, Bergen, Norway \\ (marte.stromme@uib.no) \\ Peter H. Voss, The Geological Survey of Denmark and Greenland, Copenhagen, Denmark (pv@ geus.dk) \\ Trine Dahl-Jensen, The Geological Survey of Denmark and Greenland, Copenhagen, Denmark \\ (tdj@geus.dk)
}

This paper is the final, accepted manuscript of a paper published in Seismological Research Letters under the DOI https://doi.org/10.1785/0220200471. 


\title{
Improved Seismic Monitoring with OBS Deployment in the Arctic: A Pilot Study from Offshore Western Svalbard
}

\author{
Authors \\ Zeinab Jeddi ${ }^{1}$, Lars Ottemöller ${ }^{1}$, Mathilde B. Sørensen ${ }^{1}$, Sara Rezaei ${ }^{1}$, Steven J. Gibbons ${ }^{2}$, Marte L. \\ Strømme ${ }^{1}$, Peter H. Voss ${ }^{3}$, Trine Dahl-Jensen ${ }^{3}$ \\ ${ }^{1}$ Dept. of Earth Science, University of Bergen, Bergen, Norway \\ ${ }^{2}$ Norwegian Geotechnical Institute, Oslo, Norway \\ ${ }^{3}$ The Geological Survey of Denmark and Greenland, Copenhagen, Denmark
}

\section{Corresponding Author:}

zeinab.jeddi@gmail.com

Department of Earth Science

University of Bergen

Allégaten 41, N-5007 Bergen, Norway

\section{Declaration of Competing Interests:}

The authors acknowledge there are no conflicts of interest recorded. 


\section{Abstract}

The mid-ocean ridge system is the main source of earthquakes within the Arctic region. The earthquakes are recorded on the permanent land-based stations in the region, although smaller earthquakes remain undetected. In this study, we make use of three Ocean Bottom Seismographs (OBSs) that were deployed offshore western Svalbard, along the spreading ridges. The OBS arrival times were used to relocate the regional seismicity using a Bayesian approach, which resulted in a significant improvement with tighter clustering around the spreading ridge. We also extended the regional magnitude scales for the northern Atlantic region for OBSs by computing site correction terms. Besides location and magnitude improvement, the OBS network was able to detect hundreds of earthquakes, mostly with magnitude below $\mathrm{Mw}=3$, including a swarm activity at the Molloy Deep. Our offshore observations provide further evidence of a low velocity anomaly offshore Svalbard, at the northern tip of Knipovich ridge, that was previously seen in full waveform inversion. We conclude that even a single permanent OBS near the ridge would make a significant difference to earthquake catalogs and their interpretation.

Key words: Mid-ocean ridges, earthquake monitoring, ocean bottom seismographs, ridge seismicity 


\section{Introduction}

Mid-ocean ridges play an important role in plate tectonics as that is where new oceanic lithosphere is created. The ridges make up the largest magmatic system on Earth, hosting more than 70\% of the total volcanic activity on the planet (e.g., Heezen, 1960). Numerous earthquakes occur along these plate boundaries, carrying information on the underlying tectonic and volcanic processes causing them. The largest earthquakes on the mid-ocean ridges are recorded globally, but being offshore often we lack observations at closer distances. Developments in marine science, seismology included, have over the past decades been driven by technological advances in instrumentation. Temporary Ocean Bottom Seismograph (OBS) deployments have become feasible in remote areas such as mid-ocean ridges, in order to monitor smaller earthquakes that are not detected by land-based seismic networks e.g., ETMC network (Eguchi et al., 1998 ), CYC-NET project (Bohnhoff et al., 2004), TYDE experiment (Sgroi et al., 2009), and EarthScope-Oceans (Simons et al., 2019).

Furthermore, monitoring in polar regions has become more important due to rapid changes that we are experiencing in the climate system worldwide (e.g., Stroeve et al., 2007). To investigate connections between climate and the solid Earth, one requires complete background data from continuous and long-term monitoring. To fill in gaps in the in-situ observing networks, and to improve the existing seismic catalogs, a seismological component of the EU Horizon2020 funded project INTAROS INTegrated ARctic Observation System, deployed OBSs west of Svalbard along the Arctic mid-ocean ridge (AMOR) (INTAROS, 2018).

The AMOR is a significant source of earthquakes within the Arctic Circle region (north of $66^{\circ} \mathrm{N}$ ).

It extends from Jan Mayen to the Gakkel Ridge and is a transitional ridge with a spreading rate that decreases northward from $17 \mathrm{~mm} / \mathrm{yr}$ to $7 \mathrm{~mm} / \mathrm{yr}$ (Dick et al, 2003). It consists of long segments, each with their own name and character (Figure 1). The AMOR accommodates about two hundred moderate to large $(M>4)$ earthquakes every year. The largest earthquakes $(M>\sim 4.5)$ are well recorded at teleseismic 


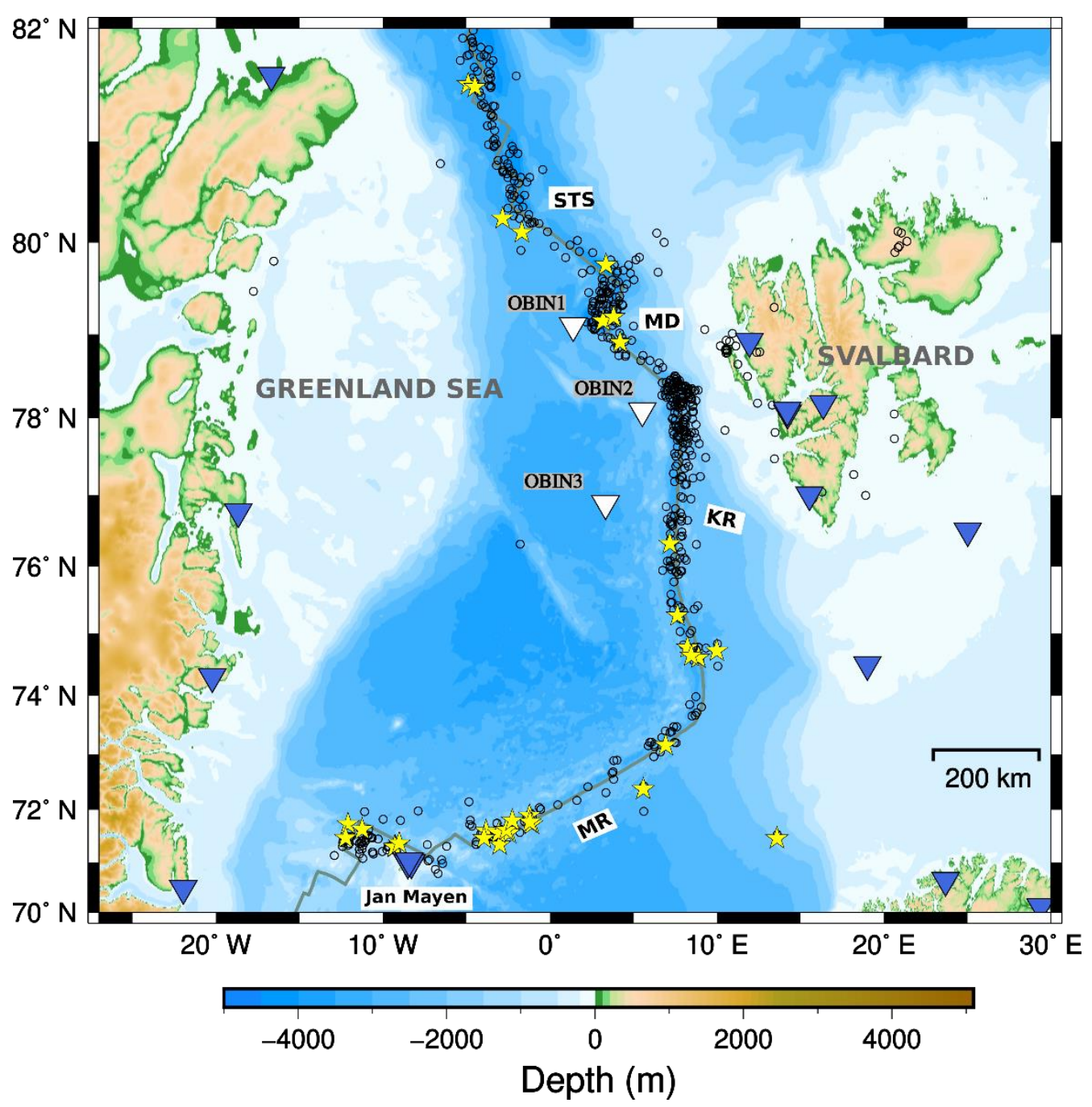

Figure 1. Arctic mid-ocean ridges and the earthquake monitoring network. Main spreading ridges are marked with their initials. MR: Mohns Ridge, KR: Knipovich Ridge, STS: Spitsbergen Transform System. MD is the location of Molloy Deep. Dark triangles: permanent regional stations. White triangles: OBS deployments. Open circles (black): regional seismicity registered in Norwegian National Seismic Network (NNSN) catalog between August 2018 and August 2019. Stars: the recorded seismicity by the National Earthquake Information Center (NEIC) between August 2018 and August 2019.

distances in addition to the permanent seismological stations in the region (e.g., National Earthquake Information Center, Figure 1). Smaller earthquakes are usually only recorded on regional stations, which at best are about $100 \mathrm{~km}$ from the earthquake epicenters where the ridge passes close to the Svalbard archipelago and the Jan Mayen volcanic island. The smallest ridge earthquakes are often not seen on land-based permanent stations and remain undetected, though they can be detected and located 
with temporary deployments of OBSs (e.g., Läderach and Schlindwein, 2011; Schlindwein et al., 2015; Pirli et al., 2018; Loviknes et al., 2020).

The regional scale improvements of earthquake catalogs along the AMOR are until now mostly done using specific location methods (e.g., Engen et al., 2003; Gibbons et al., 2017). Earthquake monitoring experiments such as the INTAROS OBSs deployment along the AMOR can in addition contribute considerably to improve seismic catalogs at the regional scale. In addition to refining earthquake locations, a few local velocity models have been produced by temporary OBS deployments (e.g., Jokat et al., 2012; Korger and Schlindwein, 2014). At a larger scale, a shear-wave velocity model of the region from full waveform inversion resolved the mid-ocean ridge and two distinct strong lowvelocity regions, beneath Iceland and the Kolbeinsey Ridge west of Jan Mayen, respectively (Rickers et al., 2013). The upper-mantle structure of the Arctic and underlying thermal anomalies were revealed by tomography together with petrological models (Lebedev et al., 2018). Moreover, several active seismic experiments have resulted in profiles along the ridges and in the spreading direction to address for example the change in crustal thickness from the spreading center towards continental crust (e.g., Kandilarov et al., 2010; Chabert et al., 2011; Krysinski et al., 2013).

In this study, we worked on data from the temporary OBS deployment along the AMOR, offshore western Svalbard, in combination with data from the land-based seismic networks. One of the key objectives was to test whether the regional earthquake catalog would be improved when adding OBS data. With such a catalog we could then analyze the observed travel times to possibly infer significant features in the velocity structure. More locally, we wanted to investigate whether the reduced detection threshold offshore western Svalbard could reveal processes that are not seen from land. Experience from the timelimited deployment allowed us to conclude on prospects for a more permanent installation along the AMOR. 


\section{Deployment and Data}

To monitor the seismicity along the AMOR, and to enhance the available regional earthquake catalogs, three OBSs were deployed under the INTAROS project. The OBSs were deployed west of the ridge for about 13 months from August 2018 (Figure 1 and Table 1). They were deployed during the INTAROS2018 cruise from the vessel KV-Svalbard by free fall in water depths of $\sim 2800 \mathrm{~m}$. We used a triangulation technique to precisely locate the instruments (e.g., Creager and Dorman, 1982). To perform the triangulation, the vessel was positioned at three different locations with $\sim 2 \mathrm{~km}$ distance from the drop point for the acoustic range measurements. In the calculations we used a constant water velocity of 1.5 $\mathrm{km} / \mathrm{s}$. The estimation showed a drift of $207 \mathrm{~m}(+/-10 \mathrm{~m})$ between the drop point and the calculated location for each instrument. Stations were named OBIN1, OBIN2 and OBIN3 from north to south and placed between $76.8^{\circ} \mathrm{N}$ and $79.1^{\circ} \mathrm{N}$ near the Molly Deep, at the northern end, and about in the middle of the Knipovich segment, respectively (Figure 1). The station locations followed the shape of the ridge, according to bathymetry and seismicity, with a spacing of about $200 \mathrm{~km}$. OBIN3 was located at a larger distance $(\sim 80 \mathrm{~km})$ from the ridge than OBIN1 and OBIN2, with $\sim 13$ and $\sim 20 \mathrm{~km}$, respectively.

Table 1. Overview of the location information after the triangulation process, deployment/recovery dates and the measured skew-time for the three OBS stations.

\begin{tabular}{|l|c|c|c|c|c|c|c|}
\hline Station & Latitude $\left(^{\circ}\right)$ & Longitude $\left(^{\circ}\right)$ & $\begin{array}{c}\text { Depth } \\
\text { below }(\mathbf{m})\end{array}$ & $\begin{array}{c}\text { Deployment } \\
\text { date }\end{array}$ & $\begin{array}{c}\text { Recovery } \\
\text { date }\end{array}$ & $\begin{array}{c}\text { Skew in the field } \\
(\mathbf{m i c r o s e c})\end{array}$ & $\begin{array}{c}\text { Applied skew on } \\
\text { data (micro sec) }\end{array}$ \\
\hline OBIN1 & $79.0993 \mathrm{~N}$ & $1.3888 \mathrm{E}$ & 2616 & $2018-08-01$ & $2019-08-18$ & - & -3118500 \\
\hline OBIN2 & $78.0893 \mathrm{~N}$ & $5.5260 \mathrm{E}$ & 2615 & $2018-08-01$ & $2019-08-18$ & -6023420 & -6023420 \\
\hline OBIN3 & $76.8812 \mathrm{~N}$ & $3.3266 \mathrm{E}$ & 3147 & $2018-07-31$ & $2019-08-19$ & -4382632 & -4382632 \\
\hline
\end{tabular}

All three OBSs were of type NAMMU, which are manufactured by K.U.M. (Umwelt- und Meerestechnik Kiel $\mathrm{GmbH}$ ). Each station consisted of a three-component broadband seismometer (Nanometrics Trillium compact, $120 \mathrm{~s}-50 \mathrm{~Hz}$ ) and a hydrophone (HTI-04 PCA/ULF INA200M, 100 s-8 
$\mathrm{kHz}$ ) and data were recorded by the data logger "K.U.M. 6D6". The stations recorded continuous data during the deployment at 100 samples per second. The three OBSs were successfully recovered in August 2019 by the vessel ACC Mosby and the total uptime for each station was 100\% during the deployment period. While the instruments worked well, we discovered after recovery that the vertical channel recording of OBIN3 was identical to one of the horizontals due to an equipment issue, and therefore it was eliminated from further processing. The instrument is currently under inspection by the manufacturer to investigate the problem.

The OBSs were synchronized with GPS before deployment, but during deployment timing was given by the internal clock that is expected to have linear drift. This time drift was measured by synchronizing the internal clock again after recovery (skew measurement). The timing was then corrected assuming linear drift. Skew measurements were successful for two instruments, but the time synchronizing failed at the recovery of OBIN1 (Table 1). Additional data from active seismic experiments close to the OBSs are useful to measure the time drift of deployments. Here, we had airgun data that were shot over OBIN3 a couple of days before its recovery. The arrival times of direct pressure waves emitted by the airgun and recorded by OBIN3 were used for determining the time drift. The estimated time drift verified the skew measurement at OBIN3.

In the case of failed synchronization, other methods such as ambient seismic noise cross correlation functions are often used (e.g., Hable et al., 2018; Loviknes et al., 2020). The skew measurement at OBIN2 was confirmed by cross-correlating with OBIN3 using EGF_td_toolboxm (Loviknes et al., 2020). We corrected the timing of OBIN1 (no skew measurement) in a similar way by cross-correlating with OBIN2 (Figure 2). Our inter-station distances varied between 200 and $400 \mathrm{~km}$ requiring a stack duration of 10-15 days (sliding window in increments of one day) to enhance signal-tonoise ratio of the cross-correlation functions (CCFs). We filtered the CCFs between 0.05 and $0.1 \mathrm{~Hz}$ and created the reference trace as described in Loviknes et al. (2020). The OBIN1 time drift was measured 
from the time offset of the CCFs and then applied to correct timing of the continuous data.
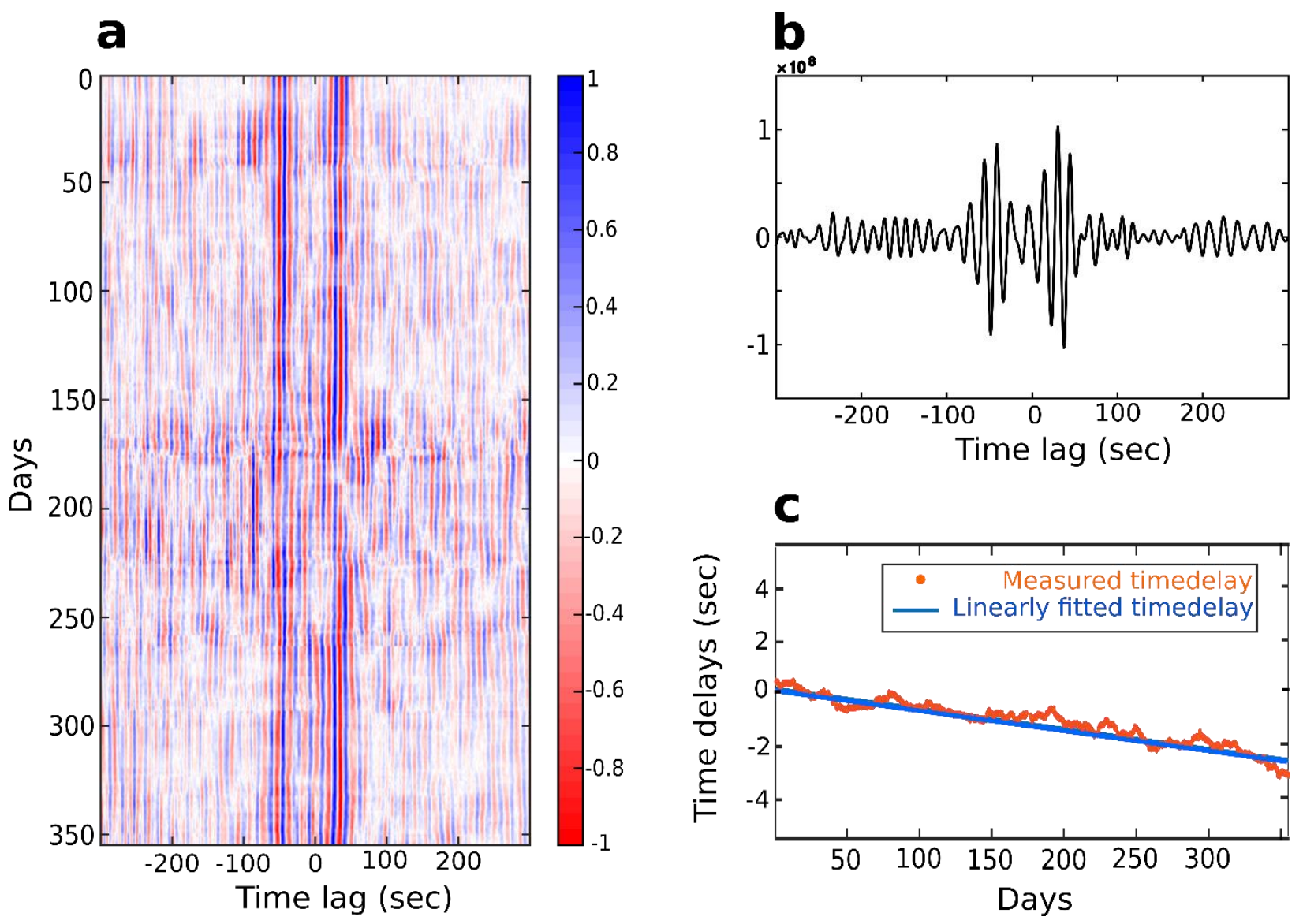

Figure 2. (a) CCFs for the vertical component between OBIN1 and OBIN2, from 1 August 2018 to 20 August 2019. The color scale shows the normalized 10-days CCF amplitude. (b) Reference trace used to measure the time shift. (c) Time shift measured for the CCFs relative to the reference trace.

Instrument performance was checked by computing power spectral densities. These were calculated over hourly segments with $50 \%$ overlap for the entire deployment period. The processing was done using the methodology of McNamara and Buland (2004) implemented in the Seisan software (Havskov et al., 2020) and plotted as probability density functions (PDF) for the vertical component of the OBSs (Figure 3). The noise levels were low for an offshore deployment in that they were better than $130 \mathrm{~dB}$ at around $10 \mathrm{~Hz}$ on all components (Figure $3 \mathrm{a}-\mathrm{h})$. Long-period (>20 s) noise is below the new High-Noise Model of Peterson (1993) on the vertical channel, but higher on the horizontal channels due 
to ocean currents as expected. Both the primary and secondary microseismic peaks are observed on the vertical components at $\sim 0.07$ and $\sim 0.2 \mathrm{~Hz}$, respectively.
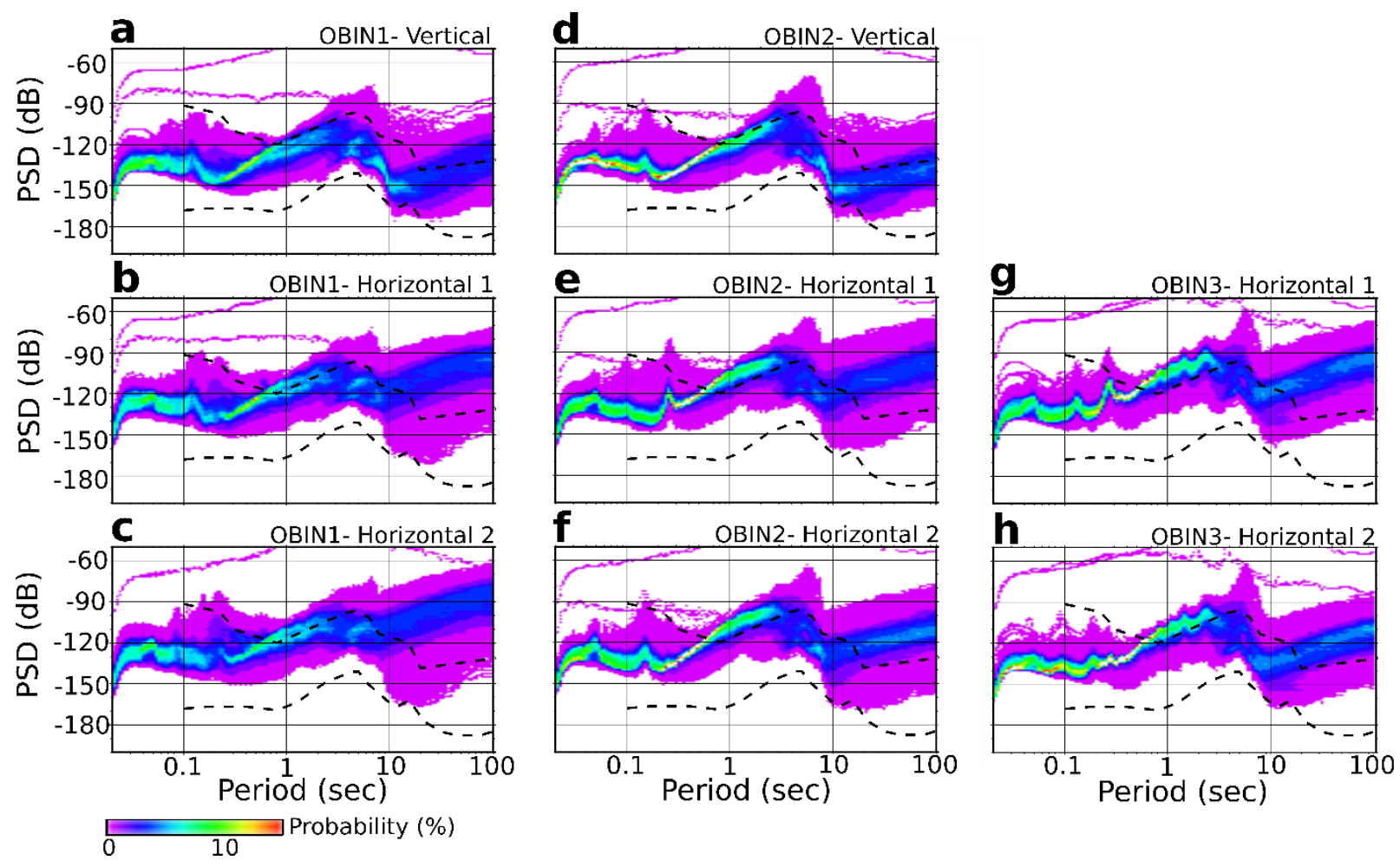

Figure 3. Noise PDFs for the OBS instruments computed for the entire recording period (August 2018-August 2019). Amplitude is computed as power acceleration and $d B$ are relative to $1\left(\mathrm{~m} / \mathrm{s}^{\wedge} 2\right)^{\wedge} 2$. The dashed black lines show the global New High- and Low-Noise Models of Peterson (1993). Each subplot is labeled with station name and corresponding component.

\section{Earthquake Catalog Improvement}

In this section, we present the different steps taken to improve the earthquake catalog. This includes the detection of additional events based on the OBSs, combining the OBS arrival times with the regional catalog, single event location and magnitude estimation. All processing is done with the Seisan software (Havskov et al., 2020) and we considered the NNSN catalog (Ottemöller et al., 2018) as baseline information. Note that data from the Danish database DNK, here the Greenland events, is routinely incorporated into NNSN. 


\section{Earthquake detection}

We expect that data from the OBSs allows us to improve event detection in and near the deployment area. In particular, we should be able to reduce the detection threshold for earthquakes along the AMOR west of Svalbard compared to using land-based stations only. We ran an automatic detection using a short-term to long-term average (STA/LTA) algorithm on the continuous data. We selected a signal-to-noise ratio threshold of 8 on bandpass filtered waveforms $(3-15 \mathrm{~Hz})$, resulting in the detection of 1347 events. The automatically detected events were manually examined before registering them into a catalog for further processing. The NNSN catalog already included 369 of the detected events, and 698 events were newly detected and locatable (observed at three or more stations, including data from land stations), mostly with a magnitude smaller than 3. The rest of the detections (280 events) were either recorded at fewer than three stations or too noisy to read phase arrivals. This clearly shows that OBSs can detect small-magnitude events that are not recorded on land stations. Figure 4 shows the cumulative number of newly detected events (locatable ones) together with events available in the NNSN catalog. Most of the newly detected events are located closer to the two stations OBIN1 and OBIN2, along the spreading ridge similar to the background seismicity (Figure 5).

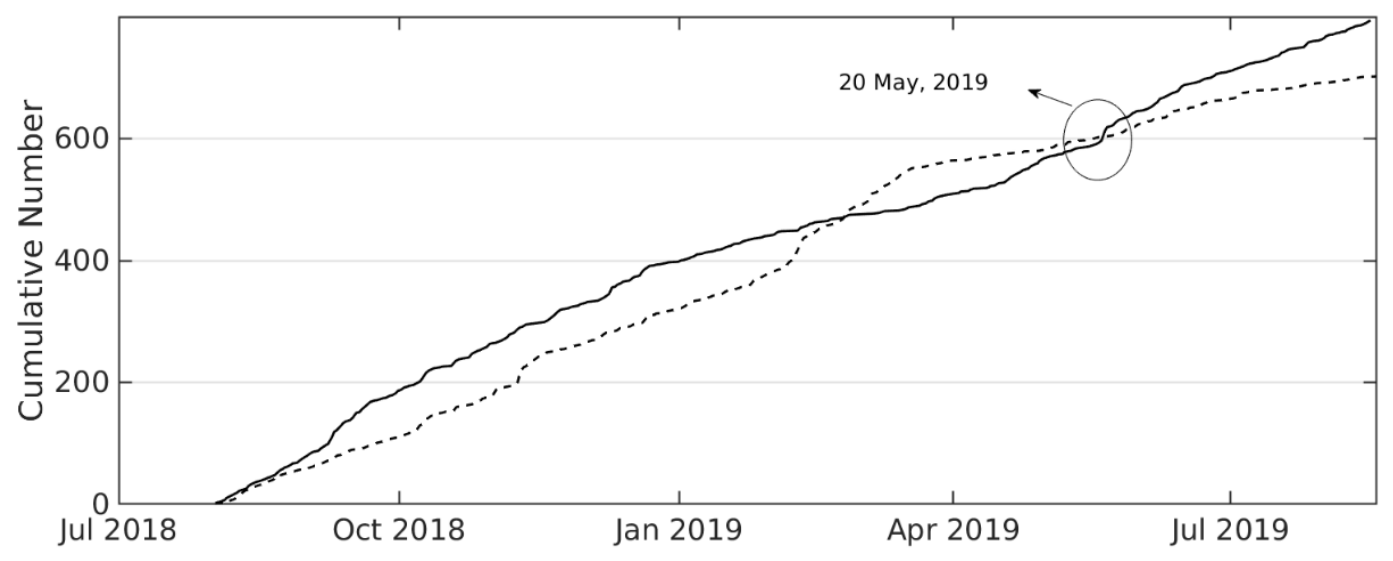

Figure 4. Cumulative number of newly detected and locatable events using OBSs (solid line) and available earthquakes in the regional NNSN catalog (dashed line) between August 2018 and August 2019. 


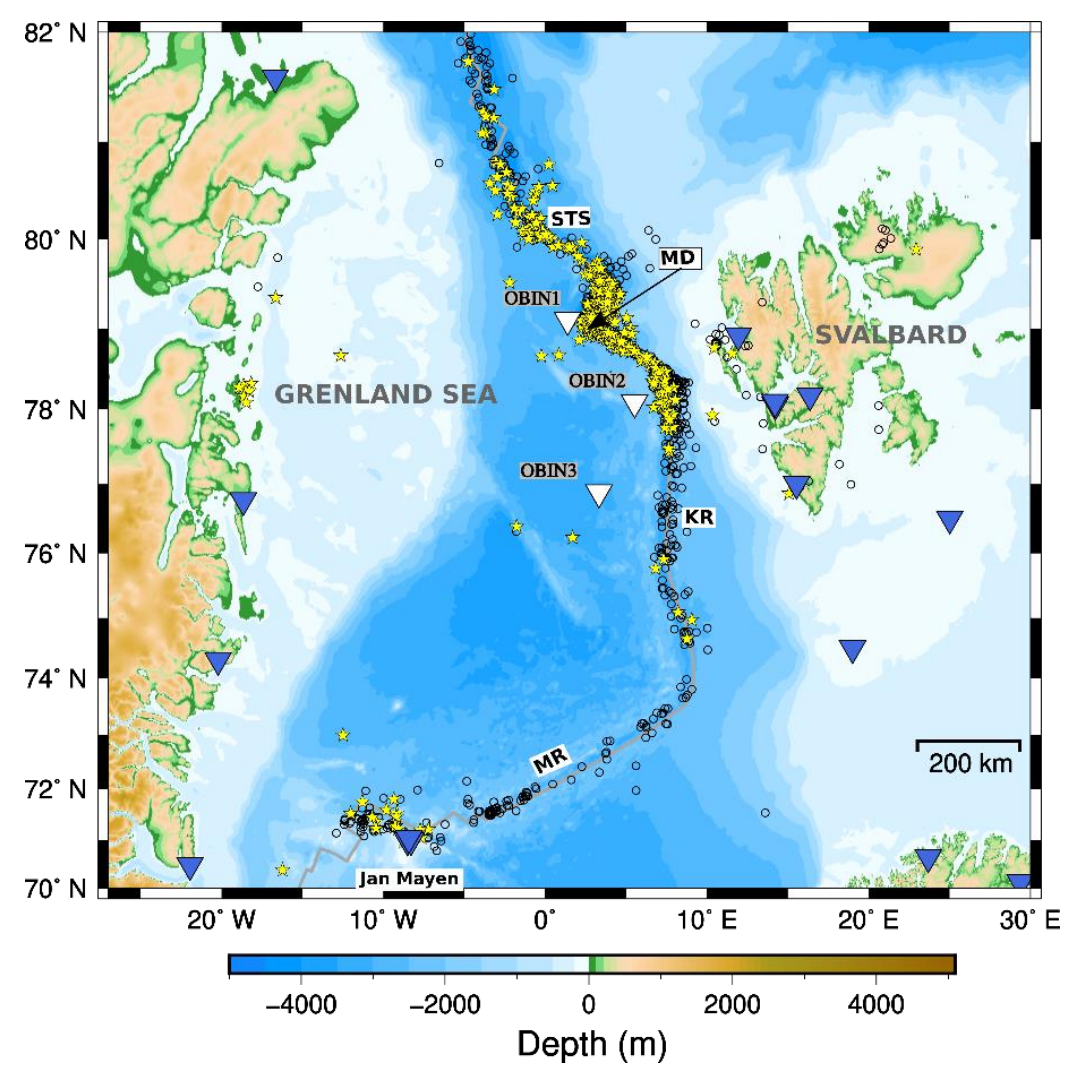

Figure 5. New detections (stars) together with regional seismicity between August 2018 and August 2019 from NNSN catalog (open circles). White triangles: OBS deployments. Dark triangles: permanent regional stations. MD refers to Molloy Deep where the most of detections are located.

The day with the highest number of newly detected events was 20 May 2019. On this day, 21 events were detected and located using the OBS deployment, with 6 of them locatable using land stations only. The events are located at the Molloy Deep (Figure 5) that formed at the intersection of the Molloy Fracture Zone and the Molloy Ridge (ridge-transform intersection). We examined the event waveforms visually and noticed high similarity between them (Figure 6). To improve the detection level, we therefore set up a cross-correlation scheme between a reference event, chosen based on high signal-to-noise ratio (inspected visually), and the continuous recordings, similar to Gibbons and Ringdal (2006). With this process running for the entire deployment period we detected 144 events, of which 86 occurred on 20 May 2019. The correlation coefficient (CC) ranged between 0.70 and 0.95 (48 events with $\mathrm{CC}>0.8$ ). Most of these earthquakes occurred within a relatively short period of time, on the small Molloy Deep segment of the spreading ridge. 


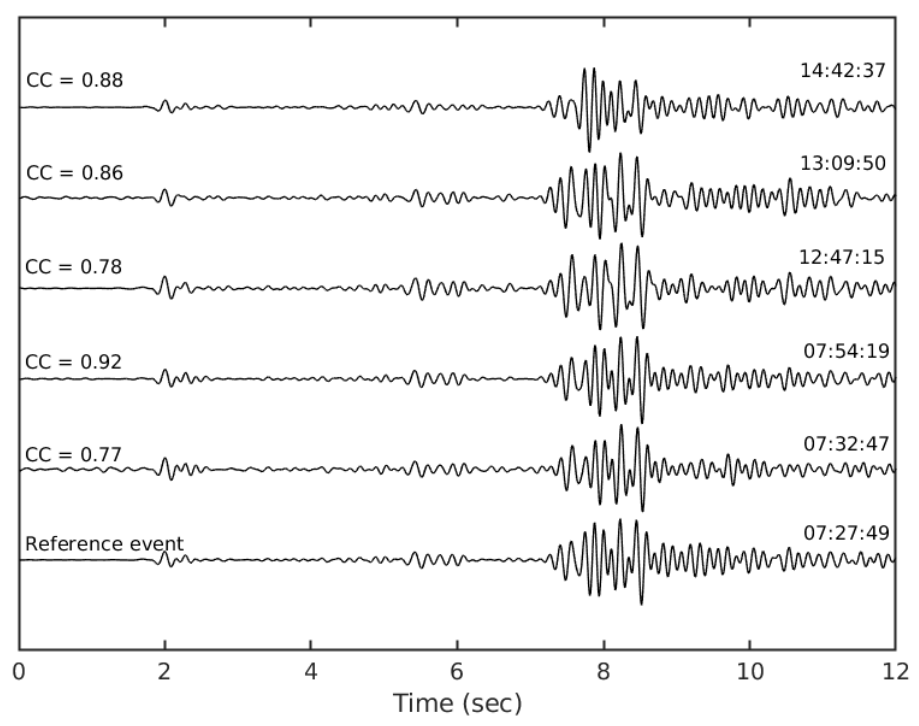

Figure 6. Example of waveforms (vertical component) from OBIN1 ( 40 km from the source) on 20 May 2019 showing their similarity. A bandpass filter of $2-10 \mathrm{~Hz}$ has been applied to the data. Zero refers approximately to 2 seconds before the first $\mathrm{P}$ arrival registered on the OBIN1. Each example is labeled with P-arrival time to the left and the correlation coefficient with the reference event to the right.

In order to look for seismic activity in the same area prior to the temporary OBS deployment, we searched for seismicity close to the Molloy deep $\left(2^{\circ}\right.$ by $2^{\circ}$ area) in the NNSN catalog since 1980 (to October 2020). We found 747 events, most of which occurred during the last decade probably due to improvements in the regional network coverage. We observed a similar level of activity to that observed on 20 May 2019 around Molloy Deep a couple of times before, this was on 4 July 2006 and on 23 September 2012 (Figure 7).

\section{Earthquake location}

The NNSN maintains a regional long-term catalog based on land-based stations that for the AMOR goes back to the 1970s. Today, the NNSN catalog for the AMOR is mostly based on about 20 permanent stations that are operated in the region including Greenland, Jan Mayen, Svalbard, Bear Island, Hopen and the Norwegian mainland (see Data and Resources for more information). The earthquake locations in the NNSN catalog are calculated using the HYPOCENTER program (Lienert et al., 1986; 
Lienert and Havskov, 1995) and a 1D velocity model given in Havskov and Bungum (1987). We added the OBS data to the NNSN catalog where possible to relocate.

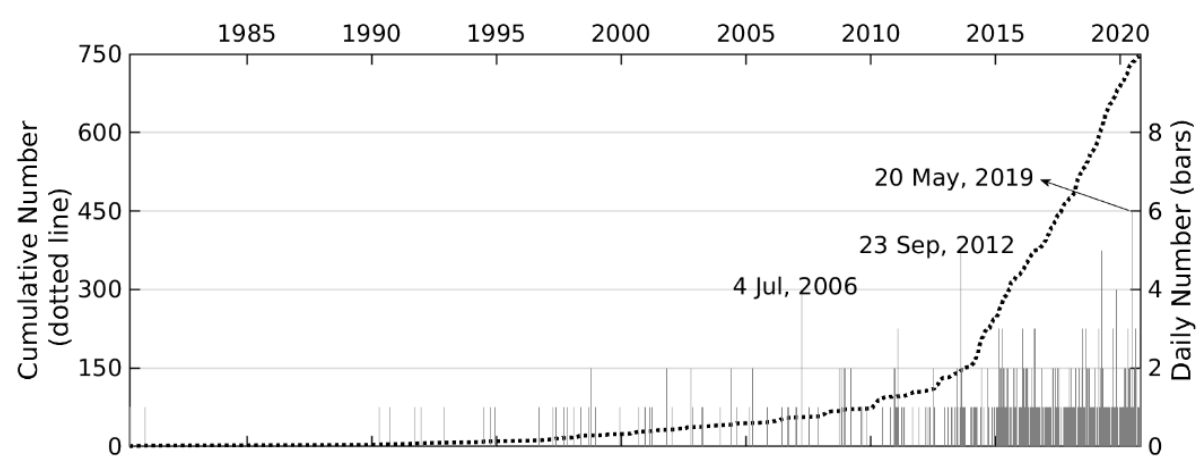

Figure 7. Daily number (bars) and the cumulative number (dottedline) of available earthquakes in the regional NNSN catalog around Molloy Deep since 1980. The selection shows located events in the regional catalog, within a $2^{\circ}$ by $2^{\circ}$ area around Molloy Deep. The days with highest activity are marked with corresponding dates.

In the event processing, we started with the larger events and then worked towards smaller magnitudes. We first selected events with M>4 between August 2018 and August 2019 (122 events). Almost all events in this group were seen clearly on the three OBSs and we could read P and S arrivals with uncertainty of the order 0.1 and $0.2 \mathrm{sec}$, respectively. The P-phases were always read on the vertical component, except for OBIN3 where the vertical component was missing. In this case, we used the hydrophone component instead. The S- and T-phases were picked on the horizontal components and the hydrophone, respectively. In addition, the T-phase was observed on vertical and hydrophone components for a larger number of events (ca. 60\%). The reading of the T-phase was added to the catalog considering the travel time, frequency and shape of observations. The same process was applied to smaller magnitude events when possible. Figure 8 shows some examples of seismograms at land stations located near the coastline (KBS on Svalbard, DAG on Greenland and JMI on Jan Mayen Island) and on the OBSs. The waveforms on land stations generally have a slightly simpler shape with a shorter coda compared to the OBS recordings, indicating more rapid decay of seismic amplitudes after the peak amplitude of the main phase, compared to those at the ocean bottom. Noticeable differences in the duration of the coda between the land stations and OBSs possibly indicate scattering or reverberation in sediments at the ocean-bottom. 
For many events, the OBSs were closer to the epicenter than any of the permanent stations, and the OBS readings were mostly consistent with the land-based data. The OBSs contributed in total to the location of 723 events. The new catalog including OBS data is compared to the original locations (only land stations) in Figure 9. It is clearly seen that the events located using OBSs are more tightly clustered around the spreading ridge, indicating better locations. Moreover, along Knipovich ridge, we have a systematic shift of epicenters by about $25 \mathrm{~km}$ to the west.
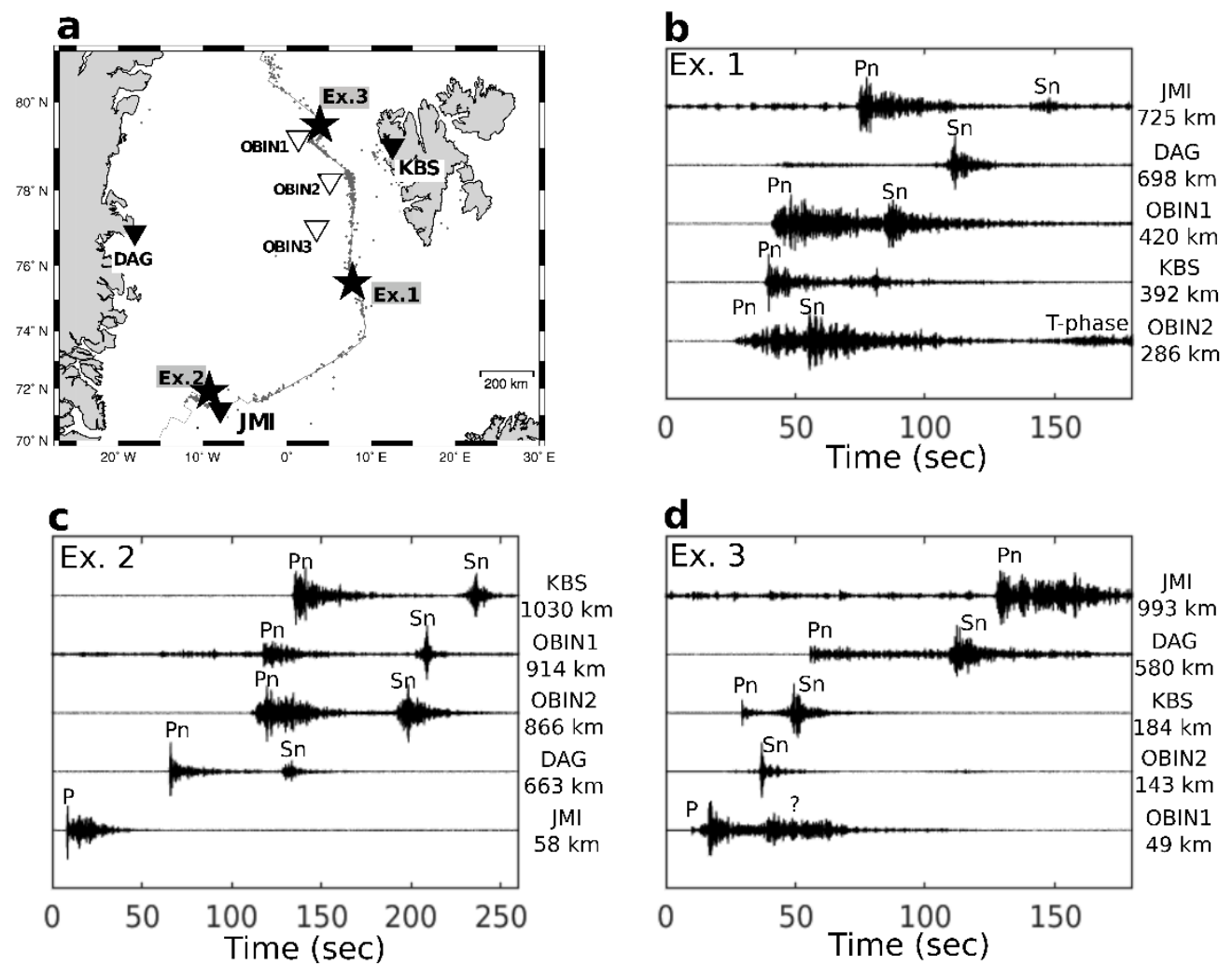

Figure 8. Examples of seismic events along the ridge. The selected earthquakes are indicated with stars and labeled with an example number in the map view. The OBS stations and other permanent stations are shown with white and dark triangles, respectively. The vertical components of seismograms are plotted for each station in b-d and the seismograms are labeled with station name and event-station distance in $\mathrm{km}$. Zero in each example refers to 10 seconds before the first $\mathrm{P}$ arrival registered for the closest station. The amplitude is normalized tracewise and the waveforms are filtered between 2 and $20 \mathrm{~Hz}$. b) Example 1 (Ex. 1): coordinates: 75.560N 7.235E, date: 21 Jun 2019 at 19:02:47, magnitude: Mw4.5. c) Example 2 (Ex. 2): coordinates: 71.368N 9.567W, date: 13 Nov 2018 at 09:06:12, magnitude: ML4.5. d) Example 3 (Ex. 3): coordinates:79.301N 3.462E, date: 11 Aug 2018 at 01:33 :07, magnitude: MN4.7. 


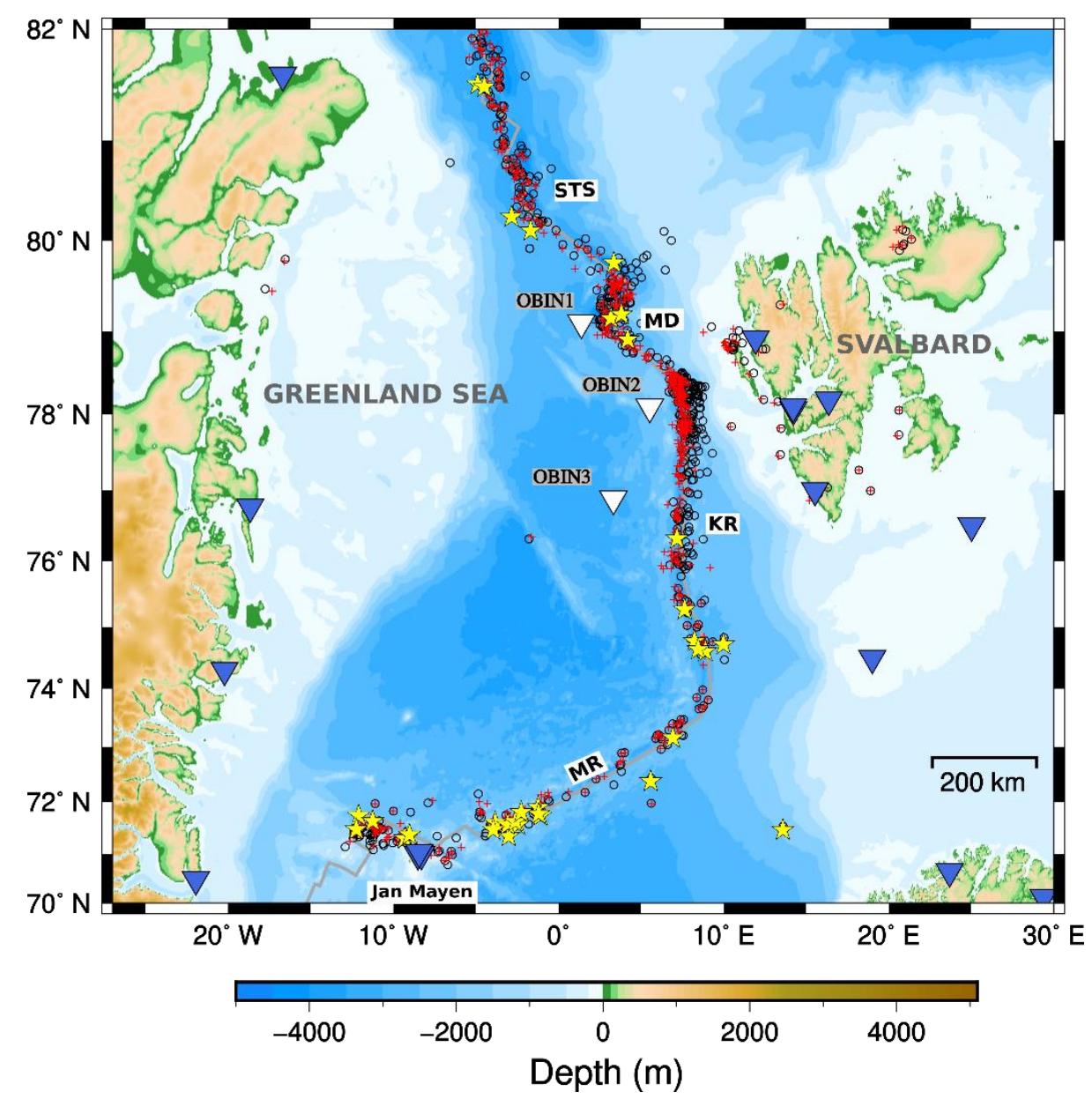

Figure 9. Seismicity between August 2018 and August 2019. Pluses (red) are event locations using both land stations and OBSs. Open circles (black) are based on only land stations. Stars are the recorded seismicity by the National Earthquake Information Center (NEIC) between August 2018 and August 2019. White triangles: OBS deployments. Dark triangles: permanent regional stations. Gray line shows the main spreading ridges which are marked with their initials. MR: Mohns Ridge, KR: Knipovich Ridge, STS: Spitsbergen Transform System. MD is the location of Molloy Deep.

\section{Magnitude estimation}

Regional magnitude scales have been developed for many continental regions, where $\mathrm{Lg} / \mathrm{Rg}$ becomes the largest amplitude phase for hypocentral distances larger than about $150 \mathrm{~km}$. However, these phases are not developed for travel paths in oceanic crust (e.g., Zhang and Lay, 1995; Bormann et al., 2013), and the standard scales cannot be readily applied. To overcome this issue, Kim and Ottemöller (2017) and Kim et al. (2020) developed regional magnitude scales for the AMOR that are based on amplitude measurements of either Pn or Sn, respectively. The scales are tied to Global Centroid Moment Tensor moment 
magnitudes (Mw) and make use of source and station correction terms such that the computed magnitude is equivalent to Mw. The NNSN has implemented these magnitude equations (label used is Mw) and use the largest amplitude of Pn or Sn to obtain station magnitudes. The event magnitude is then obtained by averaging the station magnitudes. The equations were developed using data from permanent land-based stations and not OBS recordings.

Here, we measured amplitudes as described in Kim and Ottemöller (2017) and Kim et al. (2020) using a Wood-Anderson filter on the OBS stations OBIN1 and OBIN2 for events that are in the NNSN catalog and that have a magnitude Mw assigned. From that data set, we kept Mw as computed by onshore stations and computed an average combined station residual for both OBSs. We required a minimum distance of $100 \mathrm{~km}$, which gave a total of 432 OBS amplitudes. The average magnitude residual was 0.5 , which means that the OBSs on average are giving magnitudes that are too high by this number. The station correction thus is -0.5 and was used to recompute magnitudes for the data set. The estimated correction is consistent with the study of Nakamura et al. (2014) who showed that amplification at OBS stations due to the ocean-specific structures and the presence of underlying sediment layers can result in overestimation of displacement-amplitude magnitudes of earthquakes by $\sim 0.5-0.6$.

The station correction works for regional events down to small magnitudes as long as the signal to noise ratio is high enough in the broad frequency range used by the Wood-Anderson filter. However, this scale cannot be applied for the smaller events that are located closer to the OBS stations. For these events, we follow the procedure of the NNSN to apply the regular magnitude scale for Norway (Alsaker et al., 1991). This is somewhat reasonable for events close to Svalbard recorded onshore, where a substantial part of the travel path is in continental crust. While this is arguably less correct for events that are recorded either west of or along the ridge, there is little choice until a more appropriate magnitude scale is developed. 


\section{Bayesian Earthquake Relocation}

The long-term Arctic regional earthquake catalog has been reviewed previously using revised velocity models and probabilistic methods (Engen et al., 2003; Gibbons et al., 2017). The multiple-event relocation method, as one of them, is based on a Bayesian hierarchical method (Myers et al., 2007) where the joint probability of hypocenters and origin times, travel-time corrections, pick uncertainties and phase labels are considered in the processing. Gibbons et al. (2017) used available information from regional permanent networks and additional teleseismic data (where available) in their study to improve earthquake locations regardless of the used velocity model. The relocation procedure was done in the Bayesloc software (Myers et al., 2007 and 2009).

We applied the same procedure as Gibbons et al. (2017) on the regional NNSN catalog (described in 'Earthquake location' above) between August 2018 and August 2019. Figure 10a indicates an improvement to the HYPOCENTER solutions where the seismicity appears more clustered when locating with Bayesloc, even when the OBS data is not included. The improvement in the locations is similar when OBS arrival times are included and relocation is done with HYPOCENTER (Figure 10b). We could see little difference between HYPOCENTER and Bayesloc (Figure 10b when OBS arrivals are included. Bayesloc reduces the spread in the location estimates when only the land-based stations are available because it solves for significant corrections to the travel-time curves for each station-event pair. Given the large distances and large azimuthal gap, the shortcomings of the modelled travel-times result in substantial bias and uncertainty in the event location estimates. The OBS stations considerably reduce the azimuthal gap and provide far closer observations, reducing the significance of those travel-time biases for the location estimates. The accuracy of the single-event location estimates, when the OBS readings are available, is therefore far closer to the accuracy of the multiple-event location estimates. Multiple-event location methods will likely still provide enhanced location accuracy, even though the improvement will be more modest when the additional OBS data are available. 

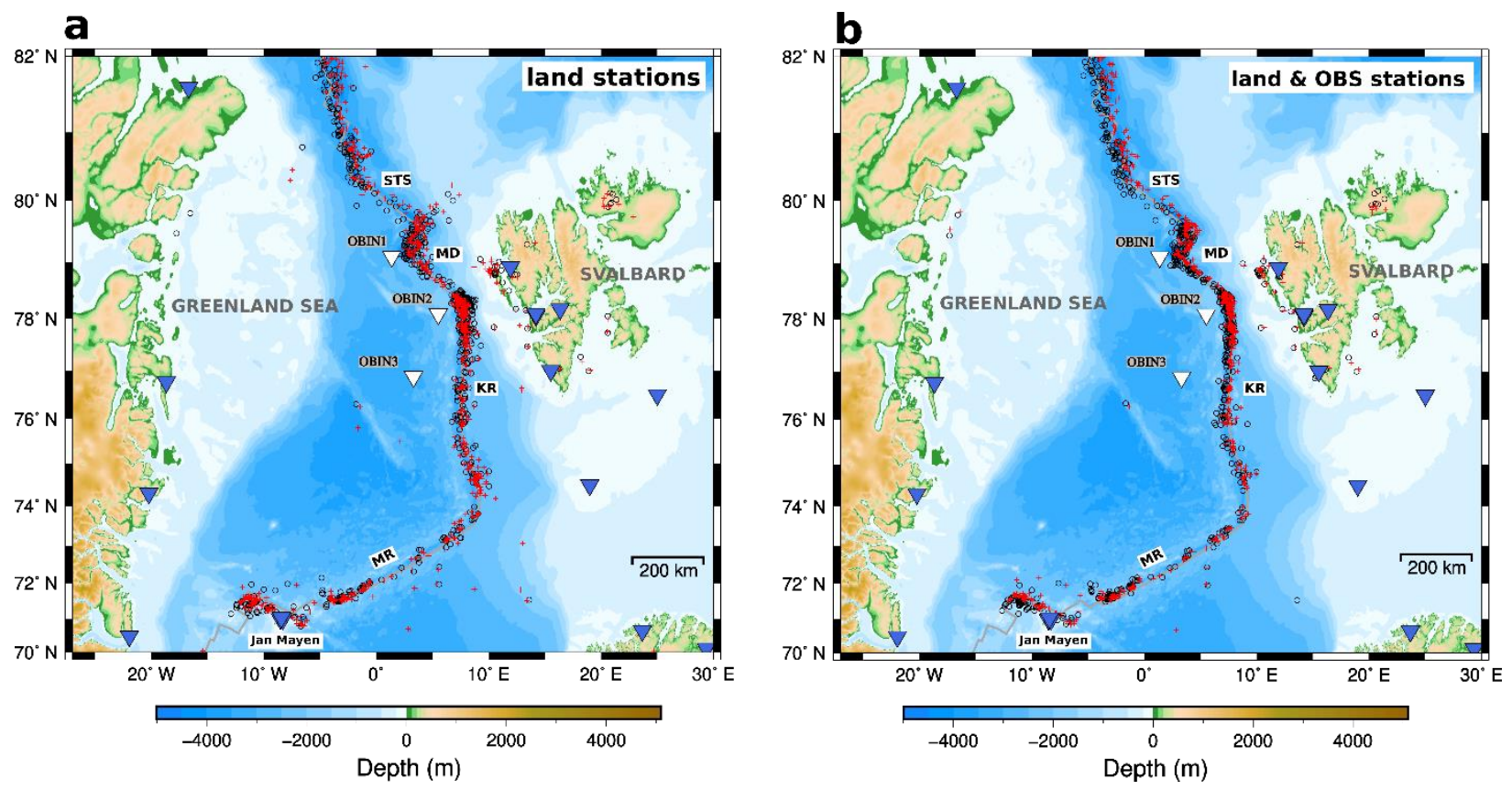

Figure 10. a) Open circles (black): HYPOCENTER solutions for the events in the regional NNSN catalog using only land stations,Pluses (red): Bayesloc solutions for data shown as open circles. b) Open circles (black): HYPOCENTER solutions for the events in the regional NNSN catalog using both land stations and OBSs. Pluses (red): Bayesloc solutions for data shown as open circles. The events were recorded between August 2018 and August 2019.

While exploring residuals of the final relocated solutions, we noticed that some events had high residuals at the OBS stations even though the signal to noise ratio was high. To check for any systematic pattern in the observed residuals, we plotted the relative residual (average residual of three OBSs subtracted from each individual residual) versus back azimuth for each station (Figure 11). We included only paths with epicentral distances larger than $130 \mathrm{~km}$ in the plot to ensure, according to our velocity model, that $\mathrm{Pn} / \mathrm{Sn}$ are the first arrivals. Figure 11 shows that events from the Jan Mayen area (backazimuth between $\sim 180$ and $\sim 220$ degrees) have higher S residuals at OBIN3 compared to other stations. 


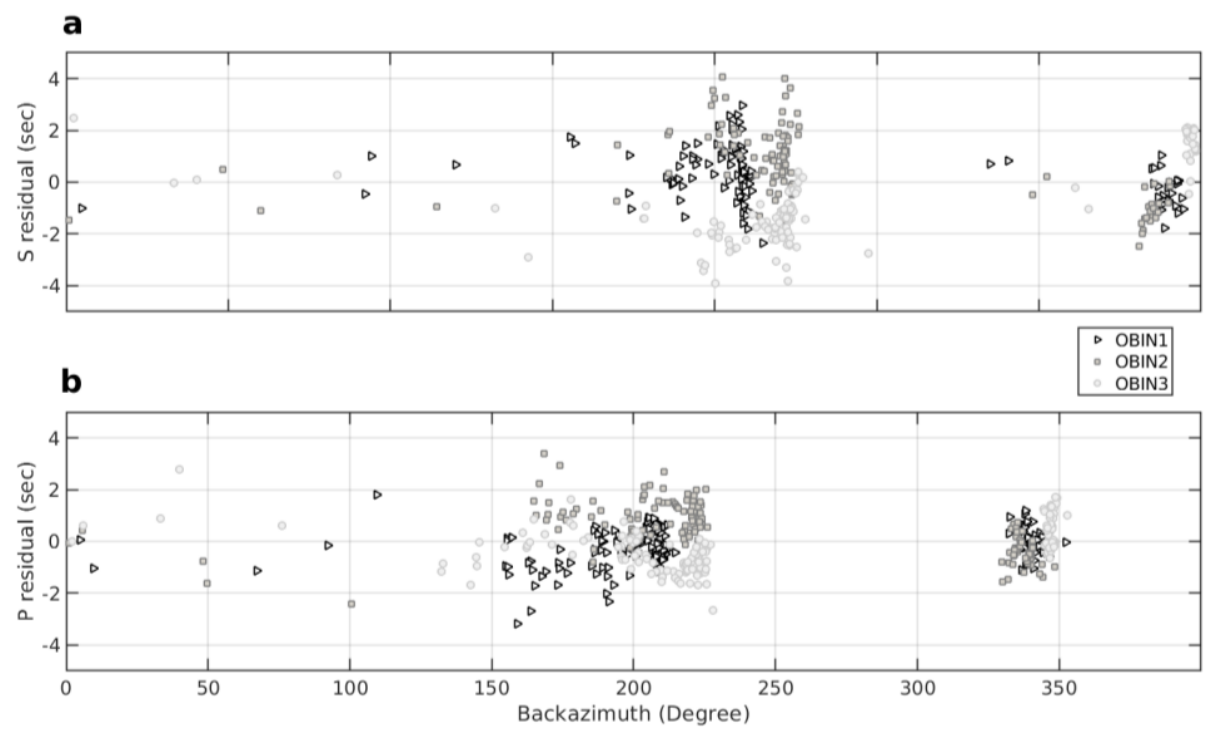

Figure 11. Relative residual versus event-station backazimuth at three OBSs a) for $\mathrm{S}$ phase, b) for $\mathrm{P}$ phase. The relative residual is the observed residual at each OBS minus the average residual of three OBSs. Only events with epicentral distances larger than $130 \mathrm{~km}$ are included in the plots.

\section{Discussion and Conclusions}

Earthquakes along the AMOR clearly define the ridge as a divergent plate boundary. However, location uncertainties when using regional and global data are of the order of tens of kilometers, which limits the scope for tectonic interpretation. Systematic errors, such as the use of inaccurate velocity models, can even result in difficulties when addressing questions such as whether the seismicity is symmetric across the ridge. Also, the detection threshold is limited due to the relatively large observational distances. These issues can be overcome with OBS deployments and, in the case of AMOR, several temporary experiments have been carried out in the past (e.g., Läderach and Schlindwein, 2011; Schlindwein et al., 2015; Loviknes et al., 2020). The target of these deployments is often the local microseismicity, and data are not always integrated with the regional networks.

Here, we demonstrate that even a small number of OBSs can contribute to improving earthquake location at a regional scale. The three OBSs were located offshore Svalbard, west of the mid-Atlantic ridge, roughly along a line with a spacing of about $200 \mathrm{~km}$. They complement the networks of permanent 
stations in Greenland, around Svalbard, on Jan Mayen and the Norwegian mainland that are integrated to monitor the regional seismicity. Previously, Gibbons et al. (2017) showed that location errors can be reduced by applying a Bayesian location procedure, resulting in the estimated distribution of the seismicity being less diffuse along the ridge. We found that a similar improvement is achieved when utilizing arrival times from the OBSs even when inverting for earthquake location with a standard tool such as HYPOCENTER. The improvement is especially significant near the northern stations, OBIN1 and OBIN2, where the earthquakes become more clustered along the spreading ridge. Many earthquakes along the ridge are recorded on stations only to the east and, given the large azimuthal gap, a location bias occurs given limitations in the velocity model. The OBS stations located to the west of the ridge seismicity reduce the azimuthal gap and diminish the influence of the offending arrival time constraints. The improved station coverage results in a westward shift of epicenters along the Knipovich ridge relative to the previous location estimates. Location algorithms which can correct for traveltime bias, such as Bayesloc, do improve the estimates further. However, this additional improvement is far more modest given the better station coverage and reduced azimuthal gap.

Apart from estimating location and size, recordings of earthquakes are also used to image the Earth's interior. In the case of the North Atlantic and part of the Arctic, Rickers et al. (2013) carried out full waveform inversion to obtain a 3D shear velocity model and identified a few low-velocity bodies. One of these was located within the upper mantle offshore central Spitsbergen around the northern tip of the Knipovich ridge. Our travel time data can be used to perform tomography, but this being outside the scope of this study, we limited ourselves to a preliminary qualitative interpretation. While we found negative residuals (i.e., arrivals earlier than expected) for all OBS stations, we noticed a significant relative difference between them. In particular, for earthquakes around Jan Mayen and along Mohns ridge, we noticed that both Pn and Sn arrivals were slowed down between OBIN3 and OBIN2 (Figure 12), which we attribute to a low-velocity body, possibly magmatic, that is present between the two stations. Earthquakes arriving from north to OBIN2 and OBIN3 are confirming our interpretation with 
paths from opposite direction. This matches the low-velocity anomaly imaged by Rickers et al. (2013), as indicated in Figure 12c.
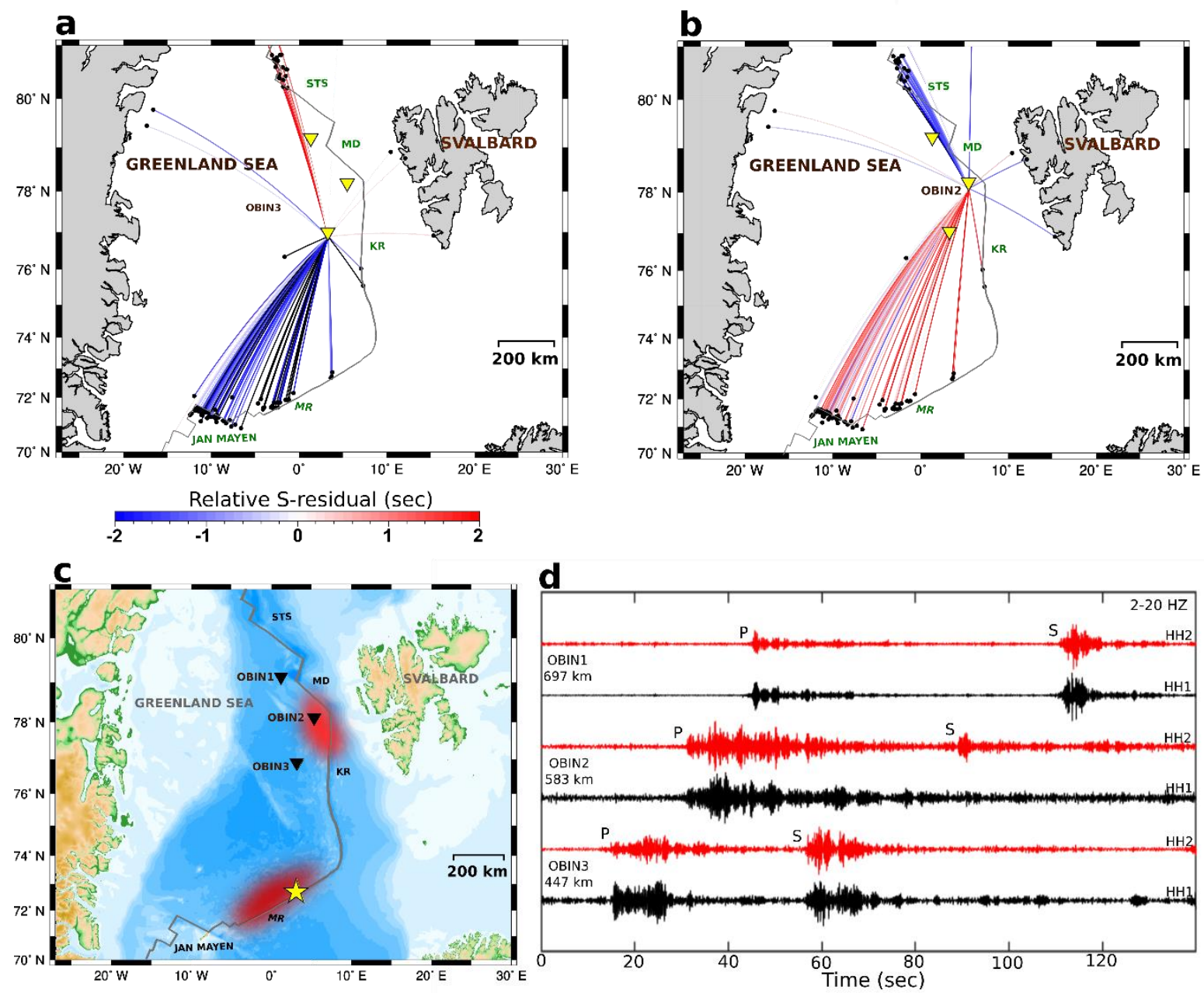

Figure 12. a) Raypath between earthquakes and OBIN3 that is colored by relative S residual. For relative residual, average residual of three OBSs was subtracted from OBIN3 individual residual. b) same as 'a' for OBIN2. Only events with epicentral distances larger than $130 \mathrm{~km}$ are included in the a and b. c) Red anomalies: Outline of low velocity anomalies at $60 \mathrm{~km}$ depth, as the shallowest section, derived from shear-wave models of Rickers at al. (2013). Black triangles: OBS deployments. d) Examples the horizontal components of a seismic event recorded at OBSs from Mohns Ridge (coordinates: 72.882N 3.800E, date: 11 Aug 2018 at 00:38:29, magnitude: MN3.9). Zero refers to 15 seconds before the first $\mathrm{P}$ arrival on OBIN3. The amplitude is normalized tracewise and the waveforms are filtered between 2 and $20 \mathrm{~Hz}$. The seismograms are labeled with station name, component name and eventstation distance in $\mathrm{km}$. The selected earthquake is shown with yellow star in panel 'c'.

The residual differences displayed in Figure 12a-b are inferred from the Bayesloc location. They are based on a 1D model with a continental crust of $31 \mathrm{~km}$ while along the ridge the crustal thickness on 
average is less than $8 \mathrm{~km}$. This presents a systematic error in travel-time calculation for the OBSs, which however is not critical when looking at the residual differences. To look for further evidence to support the hypothesis of a low-velocity body, we investigated the waveforms as we expect shear waves to be strongly attenuated when traversing a magmatic body (Figure 12d). From this, indeed we find that most earthquakes near Jan Mayen and Mohns Ridge have significantly lower S-wave amplitude on OBIN2 than on OBIN3. Differences in the waveforms could be due to the earthquake mechanism and associated radiation pattern, but this is not likely significant here as the OBS stations are in a small azimuth range.

In order to use OBS amplitudes for magnitude estimation, we calculated average amplitude residuals for the $\mathrm{mb}(\mathrm{Sn})$ equation developed by Kim et al. (2020) for events that are well recorded on the permanent stations. This scale together with $\mathrm{mb}(\mathrm{Pn})$ (Kim and Ottemöller, 2017) allows for computation of magnitude based on Sn and Pn amplitudes, respectively, that are tied to the moment magnitude through a source correction term. We found that the OBS S-wave amplitudes on average over-estimate the magnitude by 0.5 , which means that a station correction of -0.5 needs to be applied when combining with land stations. The $\mathrm{mb}(\mathrm{Pn} / \mathrm{Sn})$ scales are defined for distances beyond $100 \mathrm{~km}$ to ensure that refracted waves are developed and recorded on the land stations. Here, we did not compute magnitude for shorter distances, although that should be possible for entirely oceanic paths as is the case for ridge seismicity recorded on the OBSs.

Beyond the improvement in location at regional scale, we were able to decrease the detection threshold close to the OBSs and found hundreds of small earthquakes that follow the ridge and were missing from the regional catalogs. Out of these, most interesting was an earthquake swarm that occurred on 20 May 2019 at the Molloy Deep close to OBIN1 (Figure 5). Molloy Deep is a ridge-transform intersection and the deepest point in the Arctic Ocean at $5600 \mathrm{~m}$ (Klenke and Schenke, 2002). Previously, peaks in activity at Molloy Deep were seen in 2006 and 2012 according to the NNSN earthquake catalog. Engen et al. (2003) already described the Molloy Deep as the most seismically active part of the Spitsbergen Transform System, with clear dextral strike-slip events. 
To conclude, we demonstrate that even few OBS recordings along the Arctic mid-ocean ridge can contribute to significantly reduced location uncertainties within the region. Our results confirm that the seismic network geometry affects the quality of earthquake location more than the choice of event location algorithm. This shows that it would be a tremendous advantage to operate a seismic station along the ridge on a more permanent basis, which may become feasible with improvements in technology. We provided qualitative arguments for the hypothesis of an upper mantle low-velocity body at the northern tip of Knipovich ridge. This was previously imaged in 3D models based on full waveform inversion (Rickers et al., 2013), but deserves further investigation. Finally, we extended the earthquake catalog to smaller magnitudes for the limited time and in the vicinity of the OBS deployment. A small earthquake swarm at the Molloy Deep was spotted, in line with previous observations that this is a particularly active spot.

\section{Data and Resources}

OBS data used in this study will be released openly in March 2021 with the network code "5F" via the European Integrated Data Archive (EIDA) services. Additional information is available by contacting Lars Ottemöller (Lars.Ottemoller@uib.no) or Mathilde Sørensen (Mathilde.Sorensen@ uib.no).

Stations in Norway belong either to the University of Bergen Seismic Network (https://doi.org/10.7914/SN/NS), the Norwegian Seismic Array Network (NORSAR) (http://fdsn.org/networks/detail/NO/), the Polish Seismic Network (http://fdsn.org/networks/detail/PL/) or the Global Seismograph Network - IRIS/USGS (https://doi.org/10.7914/SN/IU). Data from the Danish Seismological Network on Greenland are available through the GEOFON Program (http://geofon.gfzpotsdam.de/fdsnws/dataselect/1/) and the IRIS Data Management Center (IRISDMC, http://service.iris.edu/fdsnws/dataselect/1/) with the network code "DK". Other stations operating in Greenland, used in this study, are accessible through the GEOFON Program (https://doi.org/10.14470/TR560404) under network code "GE". 
The earthquake catalog of the National Earthquake Information Center (NEIC) by U.S. Geological Survey was searched using https://earthquake.usgs.gov/earthquakes/search/ (last accessed Jan. 2021).

Hourly power spectral densities, probability density functions, relocation process, automatic detection and magnitude calculation are done with the open-source software SEISAN (http://seisan.info/, last accessed December 2020).

The Bayesloc multiple event location software and documentation is freely available from https://www-gs.llnl.gov/nuclear-threat-reduction/nuclear-explosion-monitoring/bayesloc (last accessed December 2020).

Detailed technical information about the OBS instrument in this study can be found at www.kumkiel.de (last accessed December 2020).

MATLAB is accessed at www.mathworks.com/products/matlab (last accessed December 2020).

The Generic Mapping Tools (Wessel et al., 2013) was used for producing most of the figures.

\section{Acknowledgement}

This study was mainly funded by the Integrated Arctic Observation System (INTAROS) project, which is funded by the European Union's Horizon 2020 Research and Innovation Program under GA No. 727890. The Norwegian National Seismic Network (NNSN) at University of Bergen has partially funded this study. OBS stations were provided by the EPOS-Norge project, funded by the Research Council of Norway. The authors acknowledge the incredible field attempt by the crew members of KV Svalbard and ACC Mosby as well as Franck Andersen, Mareile Andersson and Tarcisio Infriccioli. We also appreciate the constructive comments by the guest editor, Myrto Pirli, and two anonymous reviewers. We thank the Arctic Ice sheet monitoring program (GLISN) and International Federation of Digital Seismograph Networks (FDSN). 


\section{References}

Alsaker, A., L. B. Kvamme, R. A. Hansen, A. Dahle, and H. Bungum (1991). The ML scale in Norway. Bull. Seismol. Soc. Am. 81, no. 2, 379-398.

Bohnhoff M., M. Rische, T. Meier, B. Endrun, D. Becker, H.-P. Harjes, and G. Stavrakakis (2004). CYC-NET: A Temporary Seismic Network on the Cyclades (Aegean Sea, Greece), Seismol. Res. Lett. 75, no. 3, 352-359, doi: 10.1285/gssrl.75.3.352.

Bormann, P., S. Wendt, D. Di Giacomo (2013). Seismic Sources and Source Parameters, in New Manual of Seismological Observatory Practice 2 (NMSOP-2), P. Bormann (Editor), GFZ German Research Centre for Geosciences, Postdam, Germany. doi:10.2312/GFZ.NMSOP-2_ch3.

Chabert, A., T. A. Minshull, G. K. Westbrook, C. Berndt, K. E. Thatcher, and S. Sarkar (2011). Characterization of a stratigraphically constrained gas hydrate system along the western continental margin of Svalbard from ocean bottom seismometer data. J. Geophys. Res. 116, B12102, doi: 10.1029/2011JB008211.

Creager, K. C., and L. M. Dorman (1982). Location of instruments onthe seafloor by joint adjustment of instrument and ship positions, J. Geophys. Res. 87, 8379-8388.

Dick H. J. B., J. Lin, and H. Schouten (2003). An ultraslow-spreading class of ocean ridge. Nature 426, 405-412, doi: 10.1038/nature02128.

Eguchi, T., Y. Fujinawa, E. Fujita, S.-I. Iwasaki, I. Watabe, and H. Fujiwara (1998). A real-time observation network of ocean-bottom-seismometers deployed at the Sagami trough subduction zone, central Japan, Marine Geophysical Researches 20, 73-94, doi:10.1023/A:1004334021329.

Engen, Ø., O. Eldholm, and H. Bungum (2003). The Arctic plate boundary, J. Geophys. Res. 108, B22075, doi: 10.1029/2002JB001809.

Gibbons, S. J., D. B. Harris, T. Dahl-Jensen, T. Kværna, T. B. Larsen, B. Paulsen, and P. H. Voss 
(2017). Locating seismicity on the Arctic plate boundary using multiple-event techniques and empirical signal processing, Geophys. J. Int. 211, 1613-1627, doi: 10.1093/gji/ggx398.

Gibbons, S. J., and F. Ringdal (2006). The detection of low magnitude seismic events using array-based waveform correlation, Geophy. J. Int. 165, no. 1, 149-166, doi:10.1111/j.1365246X.2006.02865.x.

Hable, S., K. Sigloch, G. Barruol, S. C. Stahler, and C. Hadziioannou (2018). Clock errors in land and ocean bottom seismograms: High-accuracy estimates from multiple-component noise crosscorrelations, Geophys. J. Int. 214, no. 3, 2014-2034, doi: 10.1093/gji/ggy236.

Havskov, J., P. H. Voss, and L. Ottemöller (2020). Seismological observatory software: 30 Yr of SEISAN. Seismol. Res. Lett. 91, no. 3, 1846-1852, doi: 10.1785/0220190313.

Havskov, J., and H. Bungum (1987). Source parameters for earthquakes in the northern North Sea, Norsk Geologisk Tidskrift, 67, 51-58.

Heezen, B.C. (1960). The rift in the ocean floor, Sci. Am. 203, 99-110, doi: 10.1038/scientificamerican1060-98.

INTAROS (2018). Going with the floe: KV Svalbard 2018 mission to explore the Arctic Ocean, http://www.intaros.eu/stories/going-with-the-floe-kv-svalbard-2018-mission-to-explore-the-arctic-ocean/ (last accessed 2020-12-09).

Jokat, W., J. Kollofrath, W. Geissler, and L. Jensen (2012). Crustal thickness and earthquake distribution south of the Logachev Seamount, Knipovich Ridge. J. Geophys. Res. 39, L08302, doi: 10.1029/2012GL051199.

Kandilarov, A., H. Landa, R. Mjelde, R. B. Pedersen, K. Okino, and Y. Murai (2010). Crustal structure of the ultra-slow spreading Knipovich Ridge, North Atlantic, along a presumed ridge segment center. Mar. Geophys. Res. 31, 173-195, doi: 10.1007/s11001-010-9095-8.

Kim W.-Y., and L. Ottemöller (2017). Regional Pn body-wave magnitude scale mb(Pn) for 
earthquakes along the northern Mid-Atlantic Ridge, J. Geophys. Res. 122, no. 12, 10321-10340, doi: 10.1002/2017JB014639.

Kim W.-Y., L. Ottemöller, and P. G. Richards (2020). A Regional Sn Magnitude Scale mb(Sn) and Estimates of Moment Magnitude for Earthquakes along the Northern Mid-Atlantic Ridge. Bull. Seismol. Soc. Am. 110, 3158-3173, doi: 10.1785/0120190304.

Klenke M., and H. W. Schenke (2002). A new bathymetric model for the central Fram Strait, Mar. Geophys. Res. 23, 367-378, doi: 10.1023/A:1025764206736.

Korger, E. I. M., and V. Schlindwein (2014). Seismicity and structure of the $85^{\circ} \mathrm{E}$ volcanic complex at the ultraslow spreading Gakkel Ridge from local earthquake tomography, Geophys. J. Int. 196, no. 1, 539-551, doi: 10.1093/gji/ggt390.

Krysiński, L., M. Grad, R. Mjelde, W. Czuba, and A. Guterch (2013). Seismic and density structure of the lithosphere-asthenosphere system along transect Knipovich Ridge-Spitsbergen-Barents Sea-geological and petrophysical implications, Polish Polar Research 34, no. 2, 111-138, doi: 10.2478/popore-2013-0011.

Lebedev, S., A. J. Schaeffer, J. Fullea, and V. Pease (2018). Seismic tomography of the Arctic region: inferences for the thermal structure and evolution of the lithosphere, Geol. Soc. Lond., Spec. Publ. 460, 419-440, doi: 10.1144/SP460.10.

Lienert, B. R., E. Berg, and L. Neil Frazer (1986). HYPOCENTER: An earthquake location method using centered, scaled, and adaptively damped least squares. Bull. Seismol. Soc. Am. 76, no. 3, $771-783$.

Lienert, B. R., and J. Havskov (1995). A Computer Program for Locating Earthquakes Both Locally and Globally. Seismol. Res. Lett. 66, no. 5, 26-36, doi: 10.1785/gssrl.66.5.26.

Loviknes, K., Z. Jeddi, L. Ottemöller, and T. Barreyre (2020). When Clocks Are Not Working: OBS Time Correction, Seismol. Res. Lett. 91, 2247-2258, doi: 10.1785/0220190342. 
Läderach, C., and V. Schlindwein (2011). Seismic Arrays on Drifting Ice Floes: Experiences from Four Deployments in the Arctic Ocean. Seismol. Res. Lett. 82, no. 4, 494-503, doi: 10.1785/gssrl.82.4.494.

McNamara, D. E., and R. P. Buland (2004). Ambient noise levels in the continental United States. Bull. Seismol. Soc. Am. 94, 1517-1527, doi: 10.1785/012003001.

Myers S. C., G. Johannesson, and W. Hanley (2007). A Bayesian hierarchical method for multiple-event seismic location, Geophys. J. Int. 171, no. 3, 1049-1063, doi: 10.1111/j.1365246X.2007.03555.x.

Myers, S. C., G. Johannesson, G., and W. Hanley (2009). Incorporation of probabilistic seismic phase labels into a Bayesian multiple-event seismic locator, Geophys. J. Int. 177, 193-204, doi: 10.1111/j.1365-246X.2008.04070.x.

Nakamura, T., M. Nakano, N. Hayashimoto, et al. (2014). Anomalously large seismic amplifications in the seafloor area off the Kii peninsula. Marine Geophys. Res. 35, 255-270, doi; 10.1007/s11001-014-9211-2.

Ottemöller, L., M. Strømme, and B. Storheim (2018). Seismic Monitoring and Data Processing at the Norwegian National Seismic Network, Summary of the Bulletin of the International Seismological Centre, 52, no. I, 27-40, doi: 10.31905/IM97CSYL.

Peterson, J. R. (1993). Observation and modeling of seismic background noise, U.S. Geol. Surv. Tech. Rept. 93-322, 1-95, doi: 10.3133/ofr93322.

Pirli, M., J. Schweitzer, et al. (2018). Seismicity along the Mohns-Knipovich Ridge Bend and its correlation to ridge spreading rate, J. Geodyn. 118, 182-196, doi: 10.1016/j.jog.2018.01.013.

Rickers F., A. Fichtner, and J. Trampert (2013). The Iceland-Jan Mayen plume system and its impact on mantle dynamics in the North Atlantic region: Evidence from full-waveform inversion, Earth Planet. Sci. Lett. 367, 39-51, doi: 10.1016/j.eps1.2013.02.022. 
Schlindwein V., A. Demuth, E. Korger, C. Läderach, and F. Schmid (2015). Seismicity of the Arctic mid-ocean ridge system, Polar Sci. 9, 146-157, doi: 10.1016/j.polar.2014.10.001.

Sgroi, T., T. Braun, T. Dahm, and F. Frugoni (2009). An improved seismicity picture of the Southern Tyrrhenian area by the use of OBS and land-based networks: the TYDE experiment, Annals of geophysics = Annali di geofisica 49, no. 2, doi: 10.4401/ag-3130.

Simons, F. J., J. D. Simon, Y. Hello, G. Nolet, M. Obayashi, and Y. J. Chen (2019). EarthScopeOceans: An array of floating MERMAID instruments for earthquake seismology, The Journal of the Acoustical Society of America 146, no. 4, 3067-3067, doi: 10.1121/1.5137640.

Stroeve, J., M. M. Holland, W. Meier, T. Scambos, and M. Serreze (2007). Arctic sea ice decline: Faster than forecast. Geophys. Res. Lett. 34, L09501, https://doi.org/10.1029/2007GL029703.

Wessel, P., W. H. F. Smith, R. Scharroo, J. F. Luis, and F. Wobbe (2013). Generic Mapping Tools: Improved version released, Eos. Trans. AGU 94, 409-410, doi:10.1002/2013EO450001.

Zhang, T.-R. and T. Lay (1995). Why the Lg phase does not traverse oceanic crust. Bull. Seismol. Soc. Am. 85, no. 6, 1665-1678. 


\section{List of Authors}

1 Zeinab Jeddi

zeinab.jeddi@gmail.com

Department of Earth Science

University of Bergen

Allégaten 41, N-5007 Bergen, Norway

2 Lars Ottemöller

lars.ottemoller@uib.no

Department of Earth Science

University of Bergen

Allégaten 41, N-5007 Bergen, Norway

3 Mathilde B. Sørensen

mathilde.sorensen@uib.no

Department of Earth Science

University of Bergen

Allégaten 41, N-5007 Bergen, Norway

4 Sara Rezaei

sara080785@yahoo.com

Department of Earth Science

University of Bergen 
Allégaten 41, N-5007 Bergen, Norway

5 Steven J. Gibbons

steven.gibbons@ngi.no

Norwegian Geotechnical Institute

Sognsvn. 72, N-0855 Oslo, Norway

6 Marte L. Strømme

marte.stromme@uib.no

Department of Earth Science

University of Bergen

Allégaten 41, N-5007 Bergen, Norway

7 Peter H. Voss

pv@geus.dk

The Geological Survey of Denmark and Greenland

Oester Voldgade 10, 1350 Copenhagen, Denmark

8 Trine Dahl-Jensen

tdj@geus.dk

The Geological Survey of Denmark and Greenland

Oester Voldgade 10, 1350 Copenhagen, Denmark 